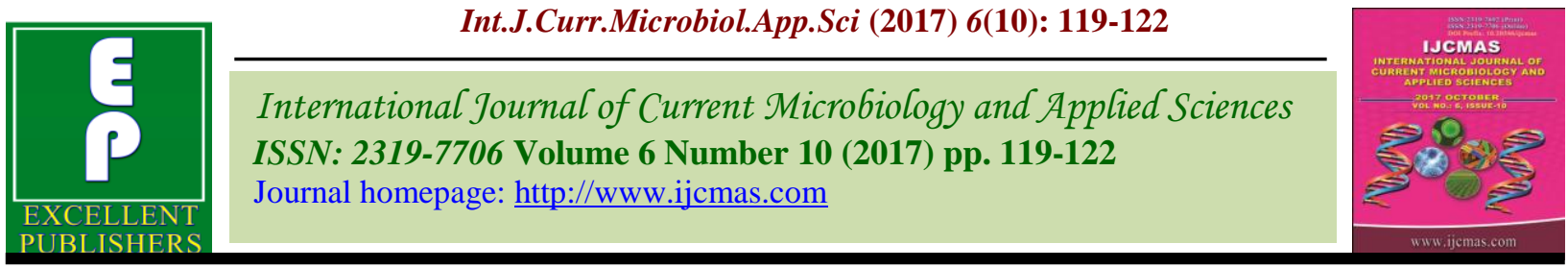

Case Study

https://doi.org/10.20546/ijcmas.2017.610.014

\title{
Clinical and Molecular Diagnosis of Johne's Disease in a Jamunapari Goat - A Case Report
}

\author{
P. Kanimozhi, M. Geetha*, K.M. Palanivel and M. Arthanari Easwaran \\ Department of Veterinary Preventive Medicine, Veterinary College and Research Institute, \\ Namakkal, Tamil Nadu, India \\ *Corresponding author
}

A B S T R A C T

Keywords

Johne's diseaes, Goat, IS 900 PCR.

Article Info

Accepted:

04 August 2017

Available Online:

10 October 2017
A 2 year old male Jamunapari goat weighing 30 kilograms was presented with complaints of chronic diarrhea, progressive weight loss and poor response to therapy. Faecal sample was collected aseptically and subjected for the presence of Mycobacterium avium subspecies paratuberculosis (MAP) by Ziehl-Neelsen staining and polymerase chain reaction (PCR). Ziehl - Neelsen staining $(\mathrm{ZN})$ revealed the presence of clumped acid fast bacilli in the faecal smears. For further differencing between Acid fast bacilli from nonacid fast MAP confirmation, DNA was extracted from faecal sample and subjected to PCR by using specific primers targeting IS 900 gene sequence of MAP and confirmed JD by detection of 413 bp PCR product.

\section{Introduction}

Johne's disease (JD) is a chronic granulomatous enteropathy of domestic and wild ruminants caused by Mycobacterium avium subspecies paratuberculosis (MAP) is of major concern in developed countries (Singh et al., 2013). It is characterized by chronic granulomatous enterocolitis, regional lymphadenitis that leads to a chronic wasting diarrhea (Clarke, 1997) and globally distributed disease except in Sweden and some states of Australia (Moges et al., 2016). Intradermal skin sensitivity test, ZiehlNeelsen staining, molecular examination of faecal and tissue samples, gross pathological examination of terminal ileum and mesenteric lymphnodes have been employed for its diagnosis (Buergelt and Ginn, 2000). The IS 900 PCR specific primer is a most widely used for targeting MAP infection (Sohal et al., 2007). The present study describes the clinical and molecular diagnosis of JD in a goat.

\section{Materials and Methods}

A three year old male Jamunapari goat maintained in an organized farm was showing progressive weight loss, emaciation, intermittent enteritis and unresponsive to therapy was presented to the Teaching 
Veterinary Clinical Complex (TVCC), Veterinary College and Research Institute (VC\&RI), Namakkal, Tamil Nadu and detailed clinical examination was carried out and about twenty grams of faecal sample was collected from rectum aseptically by using sterile gloves and submitted to the Disease diagnostic laboratory, Department of Veterinary Preventive Medicine, VC\&RI, Namakkal.

The faecal sample was centrifuged at 3000 rpm for 15 minutes. Smears were prepared from the faecal sediment and subjected to $\mathrm{ZN}$ staining technique as per the procedure described by (Manning and Collins, 2001). Using Qiagen stool mini DNA kit used for to extract DNA from the faecal sample, Polymerase chain reaction was performed as per the method described by Millar et al., (1996) using the primer set of forward: 5'GAAGGGTGTTCGGGGCCGTCGCTTAGG -3 ' and reverse: 5'-GGCGTTGAGGCGATC GCCCACGTGAC-3' targeting a DNA amplicon of $413 \mathrm{bp}$.

The amplified PCR products were electrophoresed in $1.8 \%$ agarose using TAE buffer with $80 \mathrm{v}$ for $45 \mathrm{~min}$. The DNA fragments were stained with ethidium bromide $(0.5 \mu \mathrm{g} / \mathrm{ml})$ and visualized using UVtransilluminator. The size of the amplified product was compared by 100- bp DNA ladder (Biologix).

\section{Results and Discussion}

\section{Clinical examination}

Salient features of clinical examination of the goat in this study were emaciation and enteritis with a body condition score of two. History revealed that there was a progressive weight loss in spite of normal feed intake, intermittent enteritis altered with voiding of semisolid soft faeces. This observed findings is correlating with the findings of Sharma $e t$ al., (2016) who reported that chronic enteritis, emaciation, progressive weight loss were the prominent clinical findings associated with MAP infection in goats and Windsor (2014) reported that progression of MAP infection in sheep and goats to clinical disease can results in profound weight loss, premature culling and death. Further, Sharma et al., (2016) reported that diarrheic sheep and goat infected with a JD is not a constant symptom but faeces is usually soft and emaciation which correlates with the findings in this study where the goat had intermittent diarrhea altered with voiding of soft faeces.

\section{Faecal sample examination}

\section{Ziehl - Neelsen staining}

Examination of $\mathrm{ZN}$ stained faecal smears reproducible similar morphological clumps of pink colour acid fast bacilli in the blue background (Plate -1). Tentative diagnosis of MAP infection was done based on Taylor et al., (2000) who reported that presumptive diagnosis of JD can be made if clumps of (three or more organisms) of small (0.5-1.5 um) strongly acid- fast bacilli.

Turenne et al., (2007) reported that only a small proportion of cases can be confirmed on microscopic examination of a single faecal sample. Sensitivity of the test is very low if used in preclinical stages of paratuberculosis but it is helpful when clinical phase starts (Ansari et al., 2013). Based on clinical findings it has been noticed that the goat was in clinical phase of JD and in this stage there is excretion of numerous acid fast bacilli then those in preclinical stage. Even though Z-N staining technique revealed the infection status of the goat with MAP, due to decreased sensitivity and specificity of the technique further confirmation is mandatory by advanced diagnostic tests like PCR. 


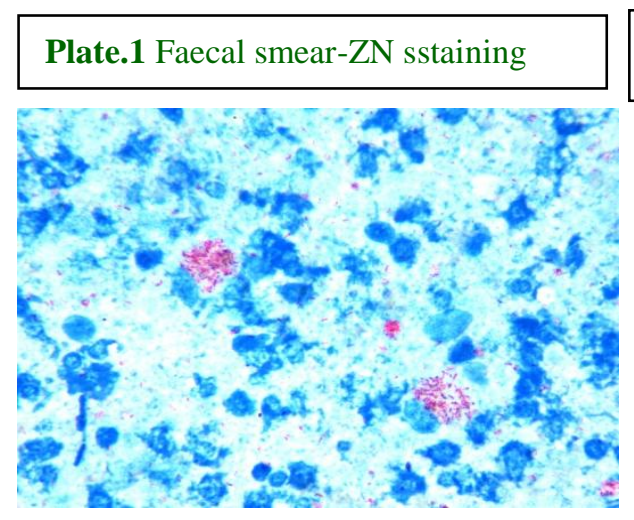

Polymerase chain reaction

Polymerase chain reaction targeting IS 900 gene sequence of MAP using gene specific primers was carried out in this study. A PCR product size of 413 bp (Plate -2) was obtained and it has been confirmed that the animal was affected with MAP beyond doubt. Sequences of IS 900 proved to be highly sensitive and specific markers of MAP among other slowly growing acid-fast bacteria because IS 900 has been detected in all reference and vaccine strains as well as in field isolates of MAP from several hosts but never in other bacterial species (Ahrens, 1995). Furthermore the use of DNA fingerprinting techniques based on IS 900 as the target sequence has been the most successful approach to the molecular characterization of MAP strains (Bauerfeind et al., 1996). Based on this it was confirmed that the goat was affected with the MAP and was in advanced clinical stage of JD which may act as a source of infection to other animals in the flock. Hence culling of the animal from the flock is highly recommended and routine screening of all animals in the flock along with routine biosecurity measures should be carried out to avoid further spread of the disease in the flock.

\section{Acknowledgements}

The authors acknowledge TANUVAS authorities for providing necessary facilities for carrying out their study.

\section{References}

Ahrens, P., Giese, S.B., Klausen, J. and Inglis, J.S. 1995. Two markers IS 901-IS902 and p40 identified by PCR and using monoclonal antibodies in Mycobacterium avium strains. J. Clin. Microbiol, 33:1049-1053.

Ansari, M.M., Peer, F.U and Wani, S.A. 2013. Studies on clinic-therapeutic management of paratuberculosis in bovine. Blue Cross Book. 29:60-61.

Bauerfeind, R., B. Samira, W. Reinhard, S. Theodor, W. Hermann and Georg baljer 1996. Molecular characterization of Mycobacterium paratuberculosis Isolates from Sheep, Goats and Cattle by Hybridization with a DNA probe to insertion element IS900, Journal of clinical microbiology, Pp. 1617-1621.

Buergelt, C.D., and P.E. Ginn 2000. The histopathologic diagnosis of subclinical Johne' disease in North American Bison (Bison bison). Veterinary Micro. 77(34): 325-331.

Clarke, C.J., 1997. The pathology and pathogenesis of paratuberculosis in ruminants and other Species. Journal of comparative pathology, 116: 217-261.

Gwodz, J., 2008, Paratuberculosis (Johne's disease). World organization for Animal health (Edn) OIE Terrestrial Manual., $\mathrm{pp}$

Lybeck, K.R., Storset, A.K, Valheim, M., and 
Oisen, I 2011. Faecal shedding detected earlier than Immune responses in goats naturally infected with Mycobacterium in India. Adv. Anim. Vet. Sci. I(6): 188190

Manning, J.B.E., Collins, M.T. 2001 Mycobacterium avium subspecies paratuberculosis pathogen, pathogenesis and diagnosis. Int Epiz.20 (1): 133-150.

Millar, D.S., J. Ford, J. Senderson, s. Withey, M. Tizard, T. Doran and J. Hermon Taylor, 1996. IS 900 PCR to detect Mycobacterium paratuberculosis in retail supplies of whole Pasteurized cow's milk in England and Wales? Appl. Environ. Microbiol, 62: 34463452.

Samuel Moges, Saddam Mohammed, Belete haile and Hayat kelifa 2016. Review on bovine Paratuberculosis. World Journal of Pharmaceutical and Medical Research, 2(5): 17-24

Sharma, Lalit and sakshi Tiwari 2016. Johne's disease: A Review Article International Journal of Recent Research in Life Sciences, Vol3 (5): 15.

Singh, S.V., Chaubey K.K, Gupta V.K,
Agarwal N.D, 2013. Co- infection of Mycobacterium avium subspecies paratuberculosis and Brucella melitensisin a sirohi breed of goats Avium subspecies paratuberculosis. Res Vet Sci 91: 32-39.

Sohal, J.S., Singh, S.V., Swati subhodh, Singh, A.V., Singh, P.K., Neelam sheoran, Komal sandhu, Narayanasamy, K. 2007. Mycobacterium avium subspecies paratuberculosis diagnosis and strain typing present status and future developments. Indian Journal of Experimental Biology.45: 843-852

Taylor, J., Bull, T., Sheridan, J.M., Cheng, J., Stellakis, M.L. and Sumar, N. 2000. Causastion of Crohn's disease by MAP. Can J Gaastroenter, 14: 521-539.

Turenne, Y., Wallace, R. and Behr, M.A. 2007. Mycobacterium avium subsp. paratuberculosis in the post genomic era. Clinical microbiological reviews, 20: 205-229.

Windsor, P.A., 2014. Effectiveness of Cudair Vaccination for the control of OJD in flocks Vaccinating for the control of OJD in flocks Vaccinating for at least 5 years. Aust. Vet. J. 92, 263-268

\section{How to cite this article:}

Kanimozhi, P., M. Geetha, K.M. Palanivel and Arthanari Easwaran, M. 2017. Clinical and Molecular Diagnosis of Johne's Disease in a Jamunapari Goat - A Case Report. Int.J.Curr.Microbiol.App.Sci. 6(10): 119-122. doi: https://doi.org/10.20546/ijcmas.2017.610.014 